\title{
KORELASI MOTIVASI DAN HASIL BELAJAR FISIKA KELAS XI MIPA SMA NEGERI 1 KUALA TUNGKAL
}

\author{
Uliya Aprily \\ Universitas Negeri Jambi \\ uliyaaprily@gmail.com \\ *koresponden author
}

\begin{abstract}
Abstrak - Penelitian ini menggunakan metode deskriptif dengan pendekatan kuantitatif yang bertujuan untuk menganalisis tentang korelasi motivasi belajar dan hasil belajar siswa SMAN 1 Kuala Tungkal tahun ajaran 2020/2021.Subjek dalam penelitian ini adalah peserta didik kelas XI MIPA SMAN 1 Kuala Tungkal yang berjumlah 62 orang.Tujuan penelitian ini untuk mengetahui gambaran motivasi belajar siswa berada pada kategori kadang-kadang,hubungan motivasi belajar dan hasil belajar siswa kelas XI SMAN 1 Kuala Tungkal.
\end{abstract}

Kata Kunci : Korelasi, Motivasi Belajar, Hasil Belajar

\begin{abstract}
This study uses a descriptive method with a quantitative approach which aims to analyze the correlation of learning motivation and student learning outcomes of SMAN 1 Kuala Tungkal in the academic year 2020/2021.The subjects in this study were 62 students of class XI MIPA at SMAN 1 Kuala Tungkal.This study is to determine the description of student learning motivation in the occasional category,the relationship between learning motivation an student learning outcomes of class XI SMAN 1 Kuala Tungkal.
\end{abstract}

Keywords : Correlation, Motivation to Learn, Learning Outcomes. 


\section{A. PENDAHULUAN}

Menurut Sisdiknas (2013) dalam kutipan Perdana et al (2019),pendidikan abad 21 sekarang sangat mengedepankan karakteristik atau perilaku dari seorang siswa.Hal ini sejalan dengan kurikulum yang diterapkan di Indonesia yaitu kurikulum K13 yang menitik beratkan kepada kemampuan efektif siswa.Bukan hanya kognitif dan psikomotorik dari siswa tersebut tetapi efektif juga dijadikan tujuan utama didalam pembelajaran.Khususnya pada pelajaran fisika dijenjang sekolah menengah atas.Pada tingkat sekolah menengah atas mempelajari berbagai ilmu pengetahuan,salah satu nya adalah fisika.

Ilmu fisika merupakan bagian dari ilmu sains,fisika banyak mempelajari obyek-obyek baik yang bersifat real maupun abstrak,obyek yang bersifat real merupakan obyek yang dapat dilihat oleh mata secara langsung bahkan dapat dilakukan eksperimen atau percobaan,sedangkan obyek yang bersifat abstrak yaitu obyek yang tidak bisa dilihat oleh mata secara langsung,sehingga perlu untuk ilustrasikan(Septian,2018).Fisika merupakan cabang ilmu pengetahuan yang dapat digunakan untuk menjawab pertanyaan mengenai fenomena menarik disekitar kehidupan manusia(Utami,Hendri \& Darmaji,2017).Dalam hal ini mata pelajaran fisika merupakan pelajaran yang menjelaskan fenomena yang terjadi didalam kehidupan sehari-hari.Mata pelajaran fisika pada dasarnya adalah memahami konsep fisika yang berupa teori,prinsip,aturan,hukum dan rumus-rumus.

Menurut Saputra et al (2019),motivasi bersifat hasil belajar (learned) yaitu perubahan yang terjadi pada perubahan emosional yang diakibatkan oleh adanya stimulus dari luar.Motivasi merupakan perilaku ke arah suatu tujuan,dengan demikian motivasi merupakan pendorong seseorang untuk lebih giat berusaha mencapai prestasi terbaiknya.Dalam penelitian ini menemukan bahwa faktor motivasi belajar berpengaruh terhadap hasil belajar siswa.Dapat dikatakan bahwa motivasi belajar terkait dengan dorongan siswa untuk terlibat aktif dalam kegiatan belajar,baik berasal dari diri siswa sendiri maupun dari luar diri siswa.

Perkembangan siswa seutuhnya menggambarkan adanya suatu perubahan dalam diri seseorang,baik itu perkembangan fisik,emosional,sosial,intelegensi maupun perkembangan spiritual yang saling berhubungan satu dengan yang lainnya.Proses belajar mengajar ini terjadi dengan melibatkan banyak faktor,baik pendidik,siswa,bahan atau materi,fasilitas maupun lingkungan.Belajar harus direncanakan,disusun dan dievaluasi hasilnya,artinya bahwa berhasil tidak pencapaian tujuan pendidikan banyak bergantung pada proses belajar dan hasilnya.Maka dari itu tujuan penelitian ini agar dapat mengetahui berhasil atau tidak nya pencapaian tujuan pendidikan didalam proses belajar mengajar.

\section{B. METODE}

Penelitian ini merupakan penelitian deskriptif kuantitatif jenis korelasional.Penelitian deskriptif kuantitatif adalah penelitian yang dimaksudkan untuk menyelidiki keadaan,kondisi atau hal lain-lain dimana data yang diperolah berupa angka-angka di peroleh berupa angka-angkayang dianalisis menggunakan statistic.Penelitian korelasional adalah penelitian yang dilakukan oleh peneliti 
untuk mengetahui tingkat hubungan antara dua variable atau lebih,tanpa melakukan perubahan,tambahan atau manipulasi terhadap data yang memang sudah ada (Arikunto,2010).

Tujuan Penelitian

Untuk mengetahui hubungan motivasi dan hasil belajar siswa dan gambaran motivasi belajar siswa kelas XI SMAN 1 Kuala Tungkal

Waktu dan Tempat Penelitian

Penelitian ini dilaksanakan di Sekolah Menengah Atas (SMA) Negeri 1 Kuala Tungkal pada semester ganjil Tahun Ajaran 2020/2021.

Subjek Penelitian

Subjek Penelitian adalah siswa kelas XI SMAN 1 Kuala Tungkal dengan jumlah siswa 62 orang.Dan variable yang di olah adalah motivasi belajar sebagai variable bebas siswa dan hasil belajar sebagai variable terikat.

Metode Penelitian

Penelitian ini merupakan penelitian deskriptif kuantitatif jenis korelasional.Penelitian deskriptif kuantitatif adalah penelitian yang dimaksudkan untuk menyelidiki keadaan,kondisi atau hal lain-lain dimana data yang diperolah berupa angka-angka di peroleh berupa angka-angkayang dianalisis menggunakan statistic.Penelitian korelasional adalah penelitian yang dilakukan oleh peneliti untuk mengetahui tingkat hubungan antara dua variable atau lebih,tanpa melakukan perubahan,tambahan atau manipulasi terhadap data yang memang sudah ada.Agar penelitian ini berjalan sesuai dengan semestinya,penelitian ini mengikuti alur yang telah dibuat sebelumnya,yaitu:

Observasi

Sebelum melakukan penelitian penulis melakukan observasi pada siswa kelas XI SMAN 1 Kuala Tungkal pada bidang studi IPA dan pokok bahasan fisika.Dan meninjau variable yang ingin diteliti yaitu motivasi belajar dan hasil belajar.

Masalah \& Pembatasan Masalah

Setelah melakukan observasi penulis melihat banyak permasalahan yang terjadi,dan penulis mendata masalah yang sesuai dengan variable yang ingin penulis teliti.Kemudian penulis membuat batasan-batasan agar permasalahan yang diteliti sesuai dengan variable dan nantinya akan memiliki hasil yang valid.

Peta Konsep

Setelah menentukan masalah dan pembatasan masalah penulis membuat dan menyusun peta konsep penelitian agar penelitian berjalan dengan benar dan tidak mengalami kesalahan yang fatal. Teknik Pengumpulan Data

Penelitian ini menggunakan angket atau kuesioner dan juga menyebarkan soal kepada siswa.Penulis mengadopsi angket dari skripsi.Angket atau kuesioner adalah sebuah cara untuk teknik yang digunakan dalam mengumpulkan data dengan menyebarkan google form yang berisi pertanyaan yang harus dijawan oleh responden,dimana dalam menggunakan metode ini pertanyaan-pertanyaan 
masalah di tulis dalam google form format kuesioner dan kemudian disebarkan kepada responden.Setelah lembar google form selesai dijawab,kemudian jawaban dikembalikan kepada peneliti.Dari jawaban tersebut peneliti akan memperoleh data terhadap masalah yang diteliti.Angket yang digunakan didalam penelitian ini merupakan jenis angket tertutup.Angket tertutup adalah sejumlah pertanyaan atau pernyataan yang telah disediakan dengan berbagai kemungkinan jawaban dan responden tinggal memilih jawaban yang paling tepat (Rukajat,2018).

Menurut Sugiyono (2009) dalam kutipan Saputra at al (2019),angket atau kuesioner merupakan teknik pengumpulan data yang dilakukan dengan cara memberikan seperangkat pertanyaan atau pernyataan tertulis kepada responden untuk dijawab.Skala Likert digunakan untuk mengukur sikap,pendapat,dan persepsi seseorang atau sekelompok orang tentang fenomena social yang disebut sebagai variable penelitian.

Untuk instrument berupa angket berisis 25 pernyataan dengan 4 skala penilian yaitu selalu,kadang-kadang,jarang,tidak pernah.Dari jumlah opsi pernyataan terbanyak yang dipilih siswa akan disimpulkan berapa tinggi motivasi yang dimiliki oleh siswa.Intrumen kedua yaitu tes hasil belajar berupa soal,yang digunakan untuk mendapatkan data hasil belajar adalah berupa tes objektif.Tes objektif yang digunakan berupa pilihan ganda (Multiple Choise Test).

Pada penelitian ini sebelum dilakukan uji hipotesis terlebih dahulu dilakukan uji normalitas dan uji regresi.Uji nomalitas untuk mengetathui apakah data penelitian yang diperoleh berdistribusi normal atau tidak.Alat yang digunakan adalah model one sample Kolmogrov-Smirnov.Hal ini bertujuan untuk memperkecil tingkat kesalahan baku dan mengetahui apakah data berdistribusi normal atau tidak.Kriteria pengambilan keputusan pada penelitian ini yaitu : jika nilai Asymp Sig (2tailed) > 0,05, maka data berdistribusi normal.Uji linearitas untuk mengetahui apakah data penelitian tersebut linear atau tidak,criteria pengambilan keputusan jika nilai Sig $>0,05$, maka data tersebut linear.Selanjutnya dilakukan pengujian hipotesis untuk mengatahui hubungan antara motivasi belajar (X) dan hasil belajar (Y).Dalam hal ini peneliti menggunakan uji korelasi parametric dengan kriteria pengambilan keputusan jika Sig > 0,05 maka Ho diterima dan Ha ditolak, dan jika Sig < 0,05 maka Ho ditolak dan Ha diterima.

\section{HASIL DAN PEMBAHASAN}

Penelitian ini dilakukan di SMAN 1 Kuala Tungal,dengan jumlah populasi 62 siswa.Dari data hasil peneliti yang telah dilakukan dari 62 sampel setelah di tabulasi hasilnya adalah 10 orang yang memiliki motivasi belajar tidak pernah, 8 orang memiliki motivasi belajar jarang, 23 orang memiliki motivasi belajar kadang-kadang dan 21 orang memiliki motivasi belajar selalu.Apabila disajikan dalam bentuk presentase,maka yang memiliki karakter tidak pernah sebesar 16,1\%,karakter jarang sebesar 12,9\%,karakter kadanng-kadang sebesar 37,1\% dan karakter selalu sebesar 33,9\%.Sedangkan berdasarkan skala sikap data yang diperoleh skor tertinggi adalah 95 yang berada di kategori kadangkadang,skor terendah 25 yang berada pada kategori tidak pernah,nilai mean atau rata-rata adalah 
69.919354 yang berada pada kategori kadang-kadang,hal ini berarti rata-rata siswa memiliki motivasi belajar kadang-kadang.Nilai median atau nilai tengah adalah 77,yang berarti berada pada ktegori kadang-kadang.Data hasil statistic deskriptif angket motivasi belajar siswa dapat dilihat pada Tabel 1 .

Tabel 1.Data Hasil Statistik Deskriptif Angket Motivasi Belajar

\begin{tabular}{cccccccc}
\hline & Klasifikasi & & $\%$ & Mean & Median & Min & Max \\
\cline { 1 - 3 } Rentang & Sikap & Frek & & & & & \\
\hline $25-$ & & & & & & & \\
43,75 & Tidak Pernah & 10 & 16,1 & & & & \\
$43,76-$ & & & & & & & \\
62,5 & Jarang & 8 & 12,9 & & & & \\
$62,51-$ & & & & 69.91935 & 77 & & \\
81,25 & Kadang-kadang & 23 & 37,1 & & & & \\
$81,26-$ & & & & & & & \\
100 & Selalu & 21 & 33,9 & & & & \\
\hline
\end{tabular}

1) Uji Asumsi

Menurut Ghazali (2013),tujuan dari uji normalitas adalah untuk mengetahui apakah masingmasing variable berditribusi normal atau tidak.Uji normalitas diperlukan karena untuk melakukan pengujian variable lainnya dengan mengasumsikan bahwa nilai nilai residual mengikuti distribusi normal.Jika asumsi dilanggar,maka uji statistic menjadi tidak valid dan statistic parametric tidak dapat digunakan.Santoso (2012) mengemukakan bahwa dasar pengambilan keputusan dapat dilakukan dengan probabilitas (Asymtotic Significance).Tabel 2 menunjukan data hasil uji normalitas untuk hasil belajar siswa kelas XI dan data angket kelas XI SMAN 1 Kuala Tungkal dengan menggunakan SPSS.Berdasarkan table Kolmogrov-Smirnov tersebut dapat dilihat bahwa nilai signifikansinya Asymp.Sig (2-tailed) adalah 0,200,untuk nilai sig hasil belajar dan nilai sig angket 0,200.Berdasarkan data maka diperoleh nilai sig 0,200>0,05 dan nilai sig 0,200>0,05. Oleh karena nilai sig > 0,05,maka data tersebut dapat dikatakan berdistribusi normal.

Tabel 2.Hasil Uji Normalitas

\begin{tabular}{cllllll}
\hline \multicolumn{2}{c}{ Kolmogorov-Smirnov $^{\mathrm{a}}$} & & \multicolumn{3}{l}{ Shapiro - Wilk } \\
& Statistik & Df & Sig. & Statistik & df & Sig. \\
\hline Motivasi Belajar & 0.089 & 62 & $.200 *$ & 0.963 & 62 & 0.057 \\
Hasil Belajar & 0.091 & 62 & $.200 *$ & 0.965 & 62 & 0.078 \\
\hline
\end{tabular}

Menurut Riduwan (2011),uji linearitas bertujuan untuk menguji data yang dihubungkan,apakah berbentuk garis linear atau tidak.Uji linearitas bertujuan untuk memastikan hubungan antara variable $\mathrm{X}$ dengan variable $\mathrm{Y}$ bersifat linear,kuadratik atau dalam derajat lebih tinggi.Berdasarkan data hasil uji linear untuk kelas XI SMAN 1 Kuala Tungkal dengan menggunakan 
SPSS dapat dilihat pada Tabel 3 diketahui bahwa nilai signifikansi dari data sebesar 0,925.Nilai ini menunjukkan bahwa nilai sig $>\alpha=0,925>0,05$, maka dapat disimpulkan bahwa data adalah linear.

Tabel 3,Hasil Uji Linearitas

\begin{tabular}{|c|c|c|c|c|c|c|c|}
\hline & & & $\begin{array}{c}\text { Sum of } \\
\text { Squares }\end{array}$ & $\mathrm{df}$ & $\begin{array}{l}\text { Mean } \\
\text { Square }\end{array}$ & $\mathrm{F}$ & Sig. \\
\hline \multirow{5}{*}{$\begin{array}{l}\text { Motivasi } \\
\text { Belajar } \\
* \text { Hasil } \\
\text { Belajar }\end{array}$} & Between & (Combined) & 1101.651 & 15 & 73.443 & .551 & .896 \\
\hline & & Linearity & 181.736 & 1 & 181.736 & 1.363 & .249 \\
\hline & & $\begin{array}{l}\text { Deviation } \\
\text { from } \\
\text { Linearity }\end{array}$ & 919.915 & 14 & 65.708 & .493 & .925 \\
\hline & \multicolumn{2}{|c|}{ Within Groups } & 6134.817 & 46 & 133.366 & & \\
\hline & \multicolumn{2}{|l|}{ Total } & 7236.468 & 61 & & & \\
\hline
\end{tabular}

2) Uji Hipotesis

Korelasi adalah suatu cara yang dipakai dalam statistic untuk mencari hubungan 2 variabel yang bersifat kuantitatif.Jadi korelasi digunakan untuk menentukan seberapa kuat hubungan antara variable bebas dan variable terikat.Dalam penelitian yang dilakukan taraf signifikansi menggunakan taraf signifikansi $5 \%$.Berdasarkan data hasil uji correlations atau uji hubungan dengan menggunakan SPSS dari table correlation Pearson dapat diketahui bahwa nilai signifikansi sebesar 0,044.Nilai ini menunjukkan bahwa nilai sig $<\alpha=0,044<0,05$, maka Ho ditolak atau dapat dikatakan terdapat hubungan motivasi belajar dan hasil belajar siswa kelas XI SMAN 1 Kuala Tungkal.Selain itu,peneliti juga mengukur kemampuan siswa pada materi gelombng bunyi.

Tabel 4.Korelasi motivasi belajar dan hasil belajar

\begin{tabular}{|ll|r|r|}
\hline & & $\begin{array}{r}\text { Motivasi } \\
\text { Belajar }\end{array}$ & \multicolumn{1}{c|}{$\begin{array}{c}\text { Hasil } \\
\text { Belajar }\end{array}$} \\
\hline Botivasi & Pearson & 1 & $.257^{*}$ \\
& Correlation & & \\
& Sig. (2- & & .044 \\
& tailed) & & \\
Hasil & Pearson \\
Belajar & Correlation & $.257^{*}$ & \\
& Sig. (2- & & \\
& tailed) & .044 & \\
& N & 62 & 62 \\
\hline
\end{tabular}

Setelah didapatkan skor angket dan skor hasil belajar siswa,kedua dianalisis dengan Pearson correlation.Untuk menjawab hipotesis penelitian yaitu ada tidaknya hubunngan antara motivasi belajar dan hasil belajar siswa materi gelombang bunyi,Kurniawan dan Yuniarto (2016) menyatakan 
bahwa untuk mengukur hubungan peristiwa lain diperlukan suatu analisis yang lebih mendalam,disini analisis korelasi untuk mengetahui erat tidaknya suatu hubungan antar peristiwa. Berdasarkan hasil analisis data penelitian nilai signifikansi antara motivasi belajar dan hasil belajar siswa sebesar 0,044.Dengan Pearson correlation 0,044 $<0,05$, maka Ho ditolak atau dapat dikatakan terdapat hubungan motivasi belajar dan hasil belajar siswa kelas XI SMAN 1 Kuala Tungkal.

\section{SIMPULAN}

Berdasarkan hasil penelitian dan pembahasan dapat disimpulkan sebagai berikut:

1. Gambaran motivasi belajar siswa kelas XI SMAN 1 Kuala Tungkal berada pada kategori kadang-kadang

2. Hubungan motivasi belajar dan hasil belajar siswa kelas XI SMAN 1 Kuala Tungkal

\section{DAFTAR RUJUKAN}

Arikunto,S.(2010).Prosedur Penelitian suatu Pendekatan Praktik.Jakarta: Rineka Cipta

Ghazali,I.(2013).Aplikasi analisis multivariente dengan program SPSS 21.Semarang: Badan Penerbit Universitas Diponegoro.

Hendri et al.(2019).Analisis hubungan karakter semangat kebangsaan dengan hasil belajar siswa.Jurnal Pembangunan dan Pendidikan:Fondasi dan Aplikasi.Vol.7.No.1:hal 1-5.

Kurniawan,R.,\& Yuniarto,B.(2016).Analisis regersi dasar dan penerapannya dengan R.Jakarta:Djambatan.

Perdana,dkk.(2019).Sikap dan Motivasi Siswa Pada Pelajaran Fisika di Sekolah Menengah Atas.Pancasakti Science Education journal.Vol.4No.2:hal 2.

Riduwan.(2012).Belajar Mudah Penelitian untuk Guru-Karyawan dan Peneliti Pemula.Bandung:Alfabeta.

Rukajat,A.(2018).Pendekatan penelitian kuantitatif (Quantitative research approach).Yogyakarta: Deepublish.

Santoso,S.(2012).Aplikasi SPSS pada statistik parametric.Jakarta: PT Elex Media Komputindo.

Saputra,dkk.(2019).Korelasi Motivasi Dan Hasil Belajar IPA Siswa Kelas VIII Di SMP Negeri Se-

Kecamatan Jambi Selatan.Jurnal Pendidikan Fisika.Vol.4.No.1:hal 38.

Saputra,dkk.(2019).Korelasi Motivasi Dan Hasil Belajar IPA Siswa Kelas VIII Di SMP Negeri SeKecamatan Jambi Selatan.Dalam Sugiyono,2009.Metode Penelitian Pendidikan Pendekatan Kuntitatif,Kualitatiffan R\&D.Bandung:Alfabeta.

Septian,D.(2018).Pembelajaran IPA dengan learing cycle berbantuan multimedia interaktif ditinjau dari pengetahuan awal dan gaya belajar siswa.Jurnal Pendidikan Fisika dan Sains.Vol.1.No.1:hal 1-13.

Sari,Intan Rizki.(2019).Analisis Tingkat Kemndirian Belajar Siswa Pada Mata Pelajaran Fisika Kelas XII MAN 1 Batanghari.Jurnal Pendidikan Fisika dan Teknologi.Vol.5.No.2. 
Jurnal Sains dan Pendidikan Fisika, Jilid 16 No 02 Agustus 2020

Utami,S,A.,Hendri,M.,\& Darmaji,D..(2017).Hubungan lingkungan belajar terhadap hasil belajar fisika kelas XI SMAN 1 Muaro Jambi.Jurnal EduFisika:Jurnal Pendidikan Fisika.Vol.2.No.2. 